\title{
Antimicrobial activity of stigmasterol from the stem bark of Neocarya macrophylla
}

\begin{tabular}{|c|c|}
\hline \multicolumn{2}{|l|}{ Authors: } \\
\hline \multicolumn{2}{|c|}{ Amina J. Yusuf ${ }^{1}$} \\
\hline \multicolumn{2}{|c|}{ Musa I. Abdullahi ${ }^{1}$} \\
\hline \multicolumn{2}{|c|}{ Godwin. A. Aleku² } \\
\hline \multicolumn{2}{|c|}{ Ilyasu A.A. Ibrahim³ } \\
\hline \multicolumn{2}{|c|}{ Celestina O. Alebiosu ${ }^{1}$} \\
\hline \multicolumn{2}{|c|}{ Maryam Yahaya ${ }^{4}$} \\
\hline \multicolumn{2}{|c|}{ Hajara W. Adamu 5} \\
\hline \multicolumn{2}{|c|}{ Abdulrazaq Sanusi ${ }^{6}$} \\
\hline \multicolumn{2}{|c|}{ Maria M. Mailafiya ${ }^{7}$} \\
\hline \multicolumn{2}{|c|}{ Hassan Abubakar } \\
\hline \multicolumn{2}{|l|}{ Affiliations: } \\
\hline \multicolumn{2}{|c|}{${ }^{1}$ Department of } \\
\hline \multicolumn{2}{|c|}{ Pharmaceutical and } \\
\hline \multicolumn{2}{|c|}{ Medicinal Chemistry, Usmanu } \\
\hline \multicolumn{2}{|c|}{ Danfodiyo, Nigeria } \\
\hline \multirow{3}{*}{\multicolumn{2}{|c|}{$\begin{array}{l}{ }^{2} \text { School of Chemistry, } \\
\text { Manchester Institute of } \\
\text { Biotechnology, University of } \\
\text { Manchester, United Kingdom }\end{array}$}} \\
\hline & \\
\hline & \\
\hline \multicolumn{2}{|c|}{${ }^{3}$ Department of Science } \\
\hline \multicolumn{2}{|c|}{ Laboratory Technology, } \\
\hline \multicolumn{2}{|c|}{ Abubakar Tatari Ali } \\
\hline \multicolumn{2}{|c|}{ Polytechnic, Nigeria } \\
\hline \multirow{2}{*}{\multicolumn{2}{|c|}{$\begin{array}{l}{ }^{4} \text { Raw Materials Research and } \\
\text { Development Council, Nigeria }\end{array}$}} \\
\hline & \\
\hline \multirow{3}{*}{\multicolumn{2}{|c|}{$\begin{array}{l}{ }^{5} \text { Department of Biology, } \\
\text { Shehu Shagari College of } \\
\text { Education, Nigeria }\end{array}$}} \\
\hline & \\
\hline & \\
\hline \multirow{5}{*}{\multicolumn{2}{|c|}{$\begin{array}{l}{ }^{6} \text { Department of } \\
\text { Pharmaceutical and } \\
\text { Medicinal Chemistry, } \\
\text { Ahmadu Bello University, } \\
\text { Nigeria }\end{array}$}} \\
\hline & \\
\hline & \\
\hline & \\
\hline & \\
\hline \multirow{4}{*}{\multicolumn{2}{|c|}{$\begin{array}{l}{ }^{7} \text { Department of } \\
\text { Pharmaceutical and } \\
\text { Medicinal Chemistry, Gombe } \\
\text { State University, Nigeria }\end{array}$}} \\
\hline & \\
\hline & \\
\hline & \\
\hline \multirow{3}{*}{\multicolumn{2}{|c|}{$\begin{array}{l}{ }^{8} \text { Department of Chemistry, } \\
\text { Sokoto State University, } \\
\text { Nigeria }\end{array}$}} \\
\hline & \\
\hline & \\
\hline Correspondir & \\
\hline $\begin{array}{l}\text { Amina Yusuf, } \\
\text { amynajega@ }\end{array}$ & mail.com \\
\hline Read online & \\
\hline 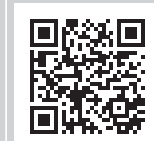 & $\begin{array}{l}\text { Scan this } Q R \\
\text { code with your } \\
\text { smart phone or } \\
\text { mobile device } \\
\text { to read online. }\end{array}$ \\
\hline
\end{tabular}

Background: Natural products play a significant role in human therapy. They represent a huge reservoir of bioactive chemical diversity and help in understanding the cellular pathways that are essential component of drug discovery process.

Objective: This study was aimed at evaluating the antimicrobial activity of stigmasterol isolated from the stem bark of Neocarya macrophylla.

Methods: Stigmasterol previously isolated from the stem bark of N. macrophylla was subjected to antimicrobial screening against methicillin-resistant Staphylococcus aureus (MRSA), vancomycin-resistant enterococci (VRE), S. aureus, Streptococcus faecalis, Escherichia coli, Salmonella typhimurium, Pseudomonas fluorescens, Klebsiella pneumoniae, Candida albicans and Candida krusei using agar diffusion and broth dilution methods.

Results: Susceptibility test results showed that the compound $(100 \mu \mathrm{g} / \mathrm{mL})$ inhibited the growth of all the test organisms with mean zone of inhibition range from $23 \mathrm{~mm}$ to $30 \mathrm{~mm}$ except the VRE, S. typhi and K. pneumoniae. The activity of stigmasterol was compared with that of ciprofloxacin $(5 \mu \mathrm{g} / \mathrm{mL})$, the standard antibacterial drug, and fluconazole $(5 \mu \mathrm{g} / \mathrm{mL})$, the antifungal agent. The test compound displayed a broad-spectrum of activity, and in many cases exhibited comparable antibacterial activity when compared to ciprofloxacin. Interestingly, the compound also showed antifungal activity against Candida spp., affording comparable inhibitory effect as fluconazole. The minimum inhibitory concentration (MIC) and the minimum bactericidal/fungicidal concentration (MBC/MFC) of stigmasterol range from $6.25 \mu \mathrm{g} / \mathrm{mL}$ to $25 \mu \mathrm{g} / \mathrm{mL}$ and from $12.5 \mu \mathrm{g} / \mathrm{mL}$ to $50 \mu \mathrm{g} / \mathrm{mL}$, respectively.

Conclusion: These properties suggest that the isolated stigmasterol is a potent and broadspectrum antibacterial and antifungal agent and as such may serve as a lead compound in the development of novel antimicrobial drugs.

\section{Introduction}

Antimicrobial resistance (AMR) driven by inappropriate use of antimicrobial agents has become a global health problem in recent years (Dryden 2017; Laxminarayan et al. 2016; Marston et al. 2016; WHO 2002). The problem of these multidrug resistance and undesirable side effects of most antibiotics necessitate the search for new antimicrobial agents of plant origin. Historically, natural products have been an important source of novel antimicrobial agents and folkloric medicinal use of these products inspired the discovery of several bioactive natural products (Li et al. 2016; Maxson et al. 2016; Simpson et al. 2016). In the last few decades, the interest of the industry in natural products has dwindled; however, in recent times, the need to tackle multidrug resistance and other emerging health problems has fuelled the rebirth of natural product drug discovery. In this regard, natural products may continue to play a vital role in antimicrobial drug discovery; therefore, there is an urgent need for novel natural product scaffolds with superior properties (Chen et al. 2016; Moloney 2016). Nature's biodiversity represents a huge reservoir of bioactive chemical diversity and has been central in the identification and development of therapeutic agents (Siddiqui et al. 2013); hence, drug discovery approaches exploiting nature's chemical diversity may uncover novel natural products with desired bioactivity (Pawar 2014).

Neocarya macrophylla (formerly Parinari macrophylla) known as Gawasa in Hausa language is widely distributed along coastal savannahs from Senegal to Liberia, and woody savannahs of

Dates: Received: 04 Oct. 2017 | Accepted: 19 Jan. 2018 | Published: 19 Mar. 2018

How to cite this article: Yusuf, A.J., Abdullahi, M.I., Aleku, G.A., Ibrahim, I.A.A., Alebiosu, I .O., Yahaya, M. et al, 2018, 'Antimicrobial activity of stigmasterol from the stem bark of Neocarya macrophylla', Journal of Medicinal Plants For Economic Development 2(1), a38. https://doi.org/10.4102/jomped.v2i1.38

Copyright: @ 2018. The Authors. Licensee: AOSIS. This work is licensed under the Creative Commons Attribution License. 


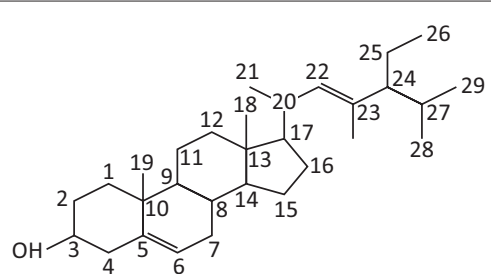

FIGURE 1: Stigmasterol (Stigmast-5, 22-dien-3ß-ol) $\mathrm{C}_{29} \mathrm{H}_{48} \mathrm{O}$.

Southern Mali, Niger and Northern Nigeria (Abonnier 2004; Burkill 1985). The plant belongs to the Chrysobalanaceae family which is composed of 17 genera, while about 525 species are found in the tropical and subtropical regions (Yakandawala, Morton and Prance 2010). N. macrophylla has been used in ethnomedicine for the treatment of a number of ailments and diseases including asthma, dysentery, diarrhoea, skin infections, cancer and ear and eye infections (Warra et al. 2013). The stem bark is extensively used in ethnomedicine in Northern Nigeria in the treatment of pain, inflammation, diarrhoea and snakebites (Amina Yusuf Jega, Department of Pharmaceutical and Medicinal Chemistry, Usmanu Danfodiyo University, Sokoto, Nigeria pers. comm. November, 2012). The antimicrobial activity of the methanol stem bark extract of the plant has been reported (Yusuf et al. 2015b). Recently, isolation and characterisation of stigmasterol (Figure 1) from the stem bark of N. macrophylla was reported (Yusuf et al. 2015a). In this study, antimicrobial activity of stigmasterol isolated from the stem bark of N. macrophylla investigated against representative gram-positive and gram-negative bacteria and two fungi is reported.

\section{Materials and Methods Isolation and structure elucidation of stigmasterol}

Stigmasterol was previously isolated from the $n$-hexane soluble fraction of the stem bark of N. macrophylla as a white crystalline solid substance using a combination of silica gel and sephadex LH-20 column. The structure was established using one-dimensional (1D) and two-dimensional (2D) nuclear magnetic resonance (NMR) spectroscopic analysis and by direct comparison of data obtained with those reported in the literature (Yusuf et al. 2015a).

\section{Antimicrobial activity of stigmasterol}

\section{Test organisms}

The antimicrobial activity of stigmasterol was determined using selected pathogenic microbes. The microbes were obtained from the Department of Medical Microbiology, Ahmadu Bello University Teaching Hospital Zaria, Kaduna State, Nigeria. All bacterial cultures were checked for purity and maintained in a blood agar slant, while the fungi were maintained on a slant of Sabouraud dextrose agar (SDA). The microbes include methicillin-resistant Staphylococcus aureus (MRSA), vancomycin-resistant enterococci (VRE), S. aureus, Streptococcus faecalis, Escherichia coli, Salmonella typhimurium, Pseudomonas fluorescens, Klebsiella pneumoniae, Candida albicans and Candida krusei.

\section{Susceptibility test}

The antimicrobial activity of the compound was carried out using stock concentration of $100 \mu \mathrm{g} / \mathrm{mL}$. Mueller Hinton agar was used as the growth medium for the microbes. The medium was prepared according to the manufacturer's instructions and sterilised at $121^{\circ} \mathrm{C}$ for $15 \mathrm{~min}$. It was poured into sterile petri dishes and then allowed to cool and solidify. The sterilised medium was seeded with $0.1 \mathrm{~mL}$ of standard inoculum of the test microbe; the inoculum was spread evenly over the surface of the medium using a sterile swab. A standard sterile cork borer of $6 \mathrm{~mm}$ diameter was used to bore a well at the centre of each inoculated medium. The wells were filled with $0.1 \mathrm{~mL}$ of the solution of the compound and allowed to diffuse for $1 \mathrm{~h}$. Incubation of the inoculated medium was made overnight at $37^{\circ} \mathrm{C}$ and $25^{\circ} \mathrm{C}$ for bacteria and fungi, respectively, after which the medium was observed for the zone of inhibition of growth; the tests were conducted in duplicates and the zone of inhibition was measured with a transparent ruler. The mean of the results was recorded in millimetres (mm) (Vollekova, Kostalova and Sochorova 2001).

\section{Minimum inhibitory concentration}

The minimum inhibitory concentration (MIC) of the compound was determined using the broth dilution method (Vollekova et al. 2001). Twofold serial dilutions of the compound in the sterile broth were made to obtain the concentrations of $100 \mu \mathrm{g} / \mathrm{mL}, 50 \mu \mathrm{g} / \mathrm{mL}, 25 \mu \mathrm{g} / \mathrm{mL}, 12.5$ $\mu \mathrm{g} / \mathrm{mL}, 6.25 \mu \mathrm{g} / \mathrm{mL}$ and $3.13 \mu \mathrm{g} / \mathrm{mL}$. An amount of $0.1 \mathrm{~mL}$ suspension of the standard inoculum of the test microbe was then inoculated into the different concentrations of the compound. The tubes were incubated at $37^{\circ} \mathrm{C}$ for $24 \mathrm{~h}$ and $25^{\circ} \mathrm{C}$ for $48 \mathrm{~h}$ for bacteria and fungi, respectively, after which the plates were observed for turbidity (growth). The MIC was defined as the lowest concentration of the compound inhibiting the visible growth of each micro-organism.

\section{Minimum bactericidal and /fungicidal concentrations}

Minimum bactericidal and fungicidal concentration was carried out to determine whether the test microbes were killed or only their growth was inhibited. Mueller Hinton agar broth was prepared, sterilised at $121^{\circ} \mathrm{C}$ for $15 \mathrm{~min}$ and transferred into sterile Petri dishes to cool and solidify. The contents of the MIC in the serial dilution were subcultured into the prepared medium and incubated at $37^{\circ} \mathrm{C}$ for $24 \mathrm{~h}$; the plates were observed for colony growth; the MBC/MFC was the plate with lowest concentration of the compound in serial dilution without colony growth (Vollekova et al. 2001).

\section{Results}

The compound, stigmasterol, exhibited varying degrees of antimicrobial activity against the test microbes. Susceptibility test result showed inhibition ranging from $23 \mathrm{~mm}$ to $30 \mathrm{~mm}$ against all the organisms, with the exception of VRE, S. typhimurium and K. pneumoniae. The compound recorded highest sensitivity against MRSA $(30 \mathrm{~mm})$ and the least sensitive organism was $P$. fluorescens $(23 \mathrm{~mm}$ ). Ciprofloxacin (5 $\mu \mathrm{g} / \mathrm{mL})$, the standard antibacterial drug, had inhibitory 
effect against all the test organisms except VRE and $P$. fluorescens with zone of inhibition of $32 \mathrm{~mm}-41 \mathrm{~mm}$, while the standard antifungal drug, fluconazole $(5 \mu \mathrm{g} / \mathrm{mL})$, exhibited activity against the two fungi species tested with inhibition range of $34 \mathrm{~mm}-35 \mathrm{~mm}$ (Table 1).

\section{Discussion}

The low MIC value $(6.25 \mu \mathrm{g} / \mathrm{mL}-25 \mu \mathrm{g} / \mathrm{mL}$, Table 2$)$ and MBC/MFC (12.5 $\mu \mathrm{g} / \mathrm{mL}-50 \mu \mathrm{g} / \mathrm{mL}$, Table 3) indicated that the compound has very good antimicrobial activity against the susceptible organisms considering the fact that compounds with MICs less than $100 \mu \mathrm{g} / \mathrm{mL}$ are regarded as having strong antimicrobial property (Tang et al. 2003). The methanol stem bark extract of $N$. macrophylla $(20 \mathrm{mg} / \mathrm{mL})$ was reported to possess good antimicrobial activity against Streptococcus pyogenes, Bacillus subtilis, Bacillus cereus, E. coli and C. albicans, with inhibition range of $22 \mathrm{~mm}-34 \mathrm{~mm}$ (Yusuf et al. 2015b); the isolated compound from this extract displayed an

TABLE 1: Susceptibility of stigmasterol to various test organisms.

\begin{tabular}{lccc}
\hline Test organism & \multicolumn{3}{c}{ Mean zone of inhibition (mm) } \\
\cline { 2 - 4 } & Stigmasterol & Ciprofloxacin & Fluconazole \\
\hline Methicillin-resistant Staphylococcus aureus & 30 & 32 & 0 \\
Vancomycin-resistant enterococci & 0 & 0 & 0 \\
Staphylococcus aureus & 29 & 35 & 0 \\
Streptococcus faecalis & 27 & 39 & 0 \\
Escherichia coli & 24 & 37 & 0 \\
Salmonella typhimurium & 0 & 41 & 0 \\
Pseudomonas fluorescens & 23 & 0 & 0 \\
Klebsiella pneumoniae & 0 & 32 & 0 \\
Candida albicans & 25 & 0 & 35 \\
Candida krusei & 27 & 0 & 34
\end{tabular}

Note: The value 0 represents no activity.

TABLE 2: Minimum inhibitory concentration of stigmasterol on the test organisms.

\begin{tabular}{lcccccc}
\hline Test organism & \multicolumn{6}{c}{ Concentration $(\mu \mathrm{g} / \mathrm{mL})$} \\
\cline { 2 - 7 } & 100 & 50 & 25 & 12.5 & 6.25 & 3.13 \\
\hline $\begin{array}{l}\text { Methicillin-resistant } \\
\text { Staphylococcus aureus }\end{array}$ & - & - & - & - & OA & + \\
Staphylococcus aureus & - & - & - & OA & + & ++ \\
Streptococcus faecalis & - & - & - & OA & + & ++ \\
Escherichia coli & - & - & OA & + & ++ & +++ \\
Pseudomonas fluorescens & - & - & OA & + & ++ & +++ \\
Candida albicans & - & - & OA & + & ++ & +++ \\
Candida krusei & - & - & - & OA & + & ++ \\
\hline
\end{tabular}

-, No turbidity (no growth); OA, minimum inhibitory concentration; +, turbidity (light growth); ++ , moderate turbidity; +++ , high turbidity.

TABLE 3: Minimum bactericidal and fungicidal concentration of stigmasterol on the test organisms.

\begin{tabular}{lcccccc}
\hline Test organism & \multicolumn{7}{c}{ Concentration $(\mu \mathrm{g} / \mathrm{mL})$} \\
\cline { 2 - 7 } & 100 & 50 & 25 & 12.5 & 6.25 & 3.13 \\
\hline $\begin{array}{l}\text { Methicillin-resistant } \\
\text { Staphylococcus aureus }\end{array}$ & - & - & - & $\mathrm{OA}$ & + & ++ \\
Staphylococcus aureus & - & - & $\mathrm{OA}$ & + & ++ & +++ \\
Streptococcus faecalis & - & - & $\mathrm{OA}$ & + & ++ & +++ \\
Escherichia coli & - & $\mathrm{OA}$ & + & ++ & +++ & +++ \\
Pseudomonas fluorescens & - & $\mathrm{OA}$ & + & ++ & +++ & +++ \\
Candida albicans & - & $\mathrm{OA}$ & + & ++ & +++ & +++ \\
Candida krusei & - & - & $\mathrm{OA}$ & + & ++ & +++ \\
\hline
\end{tabular}

, No turbidity (no growth); OA, minimum bactericidal and fungicidal concentration; +, - , No turbidity (no growth); OA, minimum bactericidal and fungicida
turbidity (light growth); ++, moderate turbidity; +++ , high turbidity. improved inhibitory effect and significantly lower MIC value when compared to the extract. The isolation and purification of stigmasterol from the stem bark extract of N. macrophylla has therefore allowed for an accurate activity evaluation of the compound, which reveals that the antimicrobial activity observed with the extract might be attributed to its stigmasterol content.

The broad-spectrum antimicrobial activity of stigmasterol observed in this study is in good agreement with previous studies. For example, Abdissa, Legesse and Delelegn (2015) reported the in vitro antibacterial activity of stigmasterol isolated from the roots of Caylusea abyssinica against S. aureus, E. coli, Pseudomonas aeruginosa and Salmonella typhimurium with zone of inhibition ranging from $11 \mathrm{~mm}$ to $18 \mathrm{~mm}$ at a higher concentration $(50 \mathrm{mg} / \mathrm{mL})$. A similar study conducted on stigmasterol gave a lower zone of inhibition $(9 \mathrm{~mm}-10 \mathrm{~mm})$ against $S$. aureus and E. coli at a concentration of $250 \mu \mathrm{g} / \mathrm{mL}$ (Tong-cun et al. 2012). Yinusa et al. (2014) also reported a zone of inhibition of $20 \mathrm{~mm}-24 \mathrm{~mm}$ for stigmasterol (at $50 \mu \mathrm{g} / \mathrm{mL}$ ) against S. aureus $(21 \mathrm{~mm})$, S. pyogenes $(22 \mathrm{~mm})$, B. subtilis (24 mm), E. coli (21 mm), Proteus vulgaris $(21 \mathrm{~mm})$, S. typhimurium $(21 \mathrm{~mm})$, S. dysenteriae $(21 \mathrm{~mm})$, C. albicans $(21 \mathrm{~mm})$, C. virusei $(20 \mathrm{~mm})$ and C. tropicalis $(20 \mathrm{~mm})$. This variability in antimicrobial activity observed for stigmasterol could be attributed to the difference in concentration of the compound used in the studies. Kanokmedhakul, Kanokmedhakul and Phatchana (2005) attributed the mechanism of action of steroids to their ability to inhibit bacterial cell surface protein 'sortase', thus preventing transpeptidation. Membrane disruption has been suggested as one of the likely mechanisms of action of sterols on microbes (Tamokou et al. 2011).

Importantly, this study represents the first antimicrobial evaluation of stigmasterol from the stem bark extract of N. macrophylla and therefore highlights an important natural source of bioactive stigmasterol in Nigeria. This study has also identified microorganisms susceptible to stigmasterol which were not previously reported. The highest activity (30 mm) exhibited by the compound on MRSA is worthy of mention as MRSA is a substantial public health problem worldwide causing morbidity and mortality and elevated health care costs. It is a leading cause of skin and soft tissue infections in patients reporting to emergency departments for treatment with a rising rate in primary care clinics and intensive care units (Green et al. 2012). MRSA has also been implicated in pneumonia and surgical site infections (Bush 1989; CDCP 2015).

The compound exhibited $29 \mathrm{~mm}$ as zone of inhibition against S. aureus, which is the most dangerous of all the many common staphylococcal bacteria and has been implicated as a causative agent in skin infections, pneumonia and breast and other fatal infections (Baorto et al. 1994). Enteropathogenic E. coli has been implicated in a number of prevalent infectious diseases including diarrhoea, dysentery (Ochoa et al. 2008) and urinary tract infection (Linhares et al. 2013). The good antibacterial activity against $E$. coli ( $24 \mathrm{~mm}$ zone of inhibition) 
displayed by the isolated stigmasterol is hence very encouraging.

Alternative therapy with herbal medicinal products and supplements has continued to increase globally, with a significant proportion of the population in developing countries relying on herbal products for health care needs. In this regard, N. macrophylla has been widely used in West Africa for the treatment of a number of diseases including dysentery, diarrhoea and skin, ear and eye infections (Warra et al., 2013). The finding of this study which showed the broad-spectrum antimicrobial activity of stigmasterol isolated from N. macrophylla establishes the efficacy of stem bark preparations of $N$. macrophylla in the treatment of those infections. However, further studies are required to address possible safety and toxicity issues with the use of N. macrophylla. Analysis of the yields of stigmasterol from stem bark of $N$. macrophylla from different regions and in different seasons should be performed. This may allow the quantification of stigmasterol content in crude extracts, which in turn may provide guidance on the posology of the herbal preparations from this plant.

\section{Conclusion}

Stigmasterol isolated from the stem bark of N. macrophylla exhibited broad-spectrum antimicrobial activity, highlighting its potential as a candidate in the development of novel antimicrobial drugs. The overall result of this study can be considered as promising with respect to discovering novel drugs from plant sources, especially when the medical importance of the tested microorganisms is considered. The results of this study have established the efficacy of the stem bark preparation of $N$. macrophylla in the management of bacterial and fungal infections.

\section{Acknowledgements}

We wish to acknowledge Dr Mika'ila of the Institute of Leather Research, Samaru, Zaria, for rendering assistance and bench space during the research.

\section{Competing interests}

The authors declare that they have no financial or personal relationships which may have inappropriately influenced them in writing this article.

\section{Authors' contributions}

A.J.Y and M.I.A. designed the research work. M.Y., H.W.A., H.A. and C.O.A. were involved in conducting the research. A.S. and M.M.M. wrote the first draft of the manuscript and all authors were involved in reviewing the final manuscript and finally it was proofread by M.I.A.

\section{References}

Abdissa, E., Legesse, A.D. \& Delelegn, W., 2015, 'In vitro antibacterial activities of compounds isolated from roots of Caylusea abyssinica', Annals of Clinical Microbiology and Antimicrobials 14, 15. https://doi.org/10.1186/s12941-0150072-6
Abonnier, M., 2004, Trees, shrubs and lianas of West African dry zones, Cidrad, Margraf Publishers, Germany, pp. 250-251.

Baorto, E.P., Baorto, D., Windle, M.L. \& Lutwick, L.I., 1994, Staphylococcus aureus infection, viewed 12 January 1994, from http://emedicine.medscape.com/ article/971358-overview

Burkill, H.M., 1985, The useful plants of West tropical Africa, Royal Botanic Gardens, Kew (K), UK. Vol. 1, pp. 1-3.

Bush, L.M., 1989. 'Best alternative to vancomycin for serious methicillin-resistant Staphylococcus aureus infections: Let's just say it', Clinical Infectious Diseases, viewed 12 June 2018, from http://cid.oxfordjournals.org/content/53/9/965.full

Centers for Disease Control and Prevention (CDC), 2015, Methicillin-resistant Staphylococcus aureus, viewed 08 January 2015, from http://www.cdc.gov/mrsa/

Chen, S., Wu, Q., Shen, Q. \& Wang, H., 2016, 'Progress in understanding the genetic information and biosynthetic pathways behind Amycolatopsis antibiotics, with implications for the continued discovery of novel drugs', ChemBioChem 17(2) 119-128. https://doi.org/10.1002/cbic.201500542

Dryden, M., 2017, 'Reactive oxygen therapy: A novel therapy in soft tissue infection', Current Opinion in Infectious Diseases 30(2), 143-149. https://doi.org/10.1097/ QCO.0000000000000350

Green, B.N., Johnson, C.D., Egan, J.T., Rosenthal, M., Griffith, E.A. \& Evans, M.W., 2012, 'Methicillin-resistant Staphylococcus aureus: An overview for manual therapists', Journal of Chiropractic Medicine 11(1), 64-76. https://doi.org/10.1016/j.jcm. 2011.12.001

Kanokmedhakul, K., Kanokmedhakul, S. \& Phatchana, R., 2005, 'Biological activity of anthraquinones and triterpenoids from Prismatomeris fragrans', Journal of Ethnopharmacology 100, 284-288. https://doi.org/10.1016/j.jep.2005.03.018

Laxminarayan, R., Sridhar, D., Blaser, M., Wang, M. \& Woolhouse, M., 2016, 'Achieving global targets for antimicrobial resistance', Science 353(6302), 874-875. https:// doi.org/10.1126/science.aaf9286

Li, G., Zhang, Z., Quan, Q., Jiang, R., Szeto, S.S., Yuan, S. et al., 2016, 'Discovery, synthesis, and functional characterization of a novel neuroprotective natura product from the fruit of Alpinia oxyphylla for use in Parkinson's disease through LC/MS-based multivariate data analysis-guided fractionation', Journal of Proteome Research 15(8), 2595-2606. https://doi.org/10.1021/acs.jproteome.6b00152

Linhares, I., Raposo, T., Rodrigues, A. \& Almeida, A., 2013, 'Frequency and antimicrobial resistance patterns of bacteria implicated in community urinary tract infections: A ten year surveillance study (2000-2009)', BMC Infectious Diseases 13, 19, viewed 12 June 2017 from http://www.biomedcentral.com/1471-2334/

Marston, H.D., Dixon, D.M., Knisely, J.M., Palmore, T.N. \& Fauci, A.S., 2016, 'Antimicrobial resistance', JAMA 316(11), 1193-1204. https://doi.org/10.1001/ jama.2016.11764

Maxson, T., Tietz, J.I., Hudson, G.A., Guo, X.R., Tai, H.C. \& Mitchell, D.A., 2016 'Targeting reactive carbonyls for identifying natural products and their biosynthetic origins', Journal of the American Chemical Society 138(46), 1515715166. https://doi.org/10.1021/jacs.6b06848

Moloney, M.G., 2016, 'Natural products as a source for novel antibiotics', Trends in Pharmacological Sciences 37(8), 689-701. https://doi.org/10.1016/j.tips.2016. 05.001

Ochoa, J.T., Barletta, F., Contreras, C. \& Mercado, E., 2008, 'New insights into the epidemiology of enteropathogenic Escherichia coli infection', Transactions of the Royal Society of Tropical Medicine \& Hygiene 102(9), 852-856. https://doi.org/ Royal Society of Tropical Medicir
$10.1016 /$ j.trstmh.2008.03.017

Pawar, H.A., 2014, 'Natural product as a source of lead to the design of new drugs', Natural Product Chemistry and Research 2, 156.

Siddiqui, A.A., Iram, F., Siddiqui, S. \& Sahu, K., 2013, 'Role of natural products in drug discovery process', International Journal of Drug Development and Research, viewed 12 June 2017, from www.ijddr.in

Simpson, B.S., Bulone, V., Semple, S.J., Booker, G.W., McKinnon, R.A. \& Weinstein, P., 2016, 'Arid awakening: New opportunities for Australian plant natural product research', The Rangeland Journal 38(5), 467-478. https://doi.org/10.1071/ RJ16004

Tamokou, J.D., Kuiate, J.R., Tene, M., Nwemeguela, T.J.K. \& Tane, P., 2011, 'The antimicrobial activities of extract and compounds isolated from Brillantais lamium', Iranian Journal of Medical Sciences 36(1), 24-31.

Tang, S., Bremner, P., Kortenkamp, A., Schlage, C., Gary, A.I., Gibbons, S. et al., 2003 Biflavonoids with cytotoxic and antibacterial activity from Ochna macrocalyx', Planta Medica 69, 247-253. https://doi.org/10.1055/s-2003-38478

Tong-cun, Z., Pinkai O., Samuel, K. \& Bil, S., 2012, 'Selects papers from domestic and foreign researchers to exchange their ideas and experiences with the applicationoriented research of biotechnology', in Proceedings of the International Conference on Applied Biotechnology (ICAB 2012) held on the 18-19 October, 2012 in Tianjin, China vol. 3, pp. 1588-1589.

Vollekova, A. Kostalova, D. \& Sochorova, R., 2001, 'Isoquinoline alkaloid from Mahonia aquifolium stem bark is active against Malsseizia species', Folia Microbiologica 46, 107-111. https://doi.org/10.1007/BF02873586

Warra, A.A. Umar, R.A., Sani, L, Gafar, M.K., Nasiru, A. \& Ado, A., 2013, 'Preliminary phytochemical screening and physicochemical analysis of gingerbread plum (Parinari macrophylla) seed oil', Journal of Pharmacognosy and Phytochemistry $1(2), 20-25$

World Health Organization (WHO), 2002, Use of antimicrobials outside human medicine and resultant antimicrobial resistance in humans, Fact sheet 268, WHO, Geneva. 
Yakandawala, D., Morton, C.M. \& Prance, G.T., 2010, 'Phylogenetic relationships of the chrysobalanaceae inferred from chloroplast, nuclear and morphological data', Annals of the Missouri Botanical Garden 97, 259-281. https://doi.org/10.3417/ 2007175

Yinusa, I., George, N.I. Shuaibu, O.A. \& Ayo, R.G., 2014, 'Bioactivity of stigmasterol isolated from the aerial part of Spillanthes acmella (Murr) on selected microorganism', International Journal of Current Microbiology and Applied Sciences $3(2), 475-479$
Yusuf, A.J., Abdullahi, M.I., Haruna, A.K., Idris, A.Y. \& Musa, A.M., 2015a, 'Isolation and characterization of stigmasterol and Bis-(5,7-diacetyl-catechin-4- $\alpha$ and characterization of stigmasterol and Bis-(5,7-diacetyl-catechin-4- $\alpha$ rhamnopyranoside) from the stem bark of Neocarya macrophylla (Sabine) prance https://doi.org/10.4314/njbas.v23i1.3

Yusuf, A.J., Abdullahi, M.I., Haruna, A.K., Musa, A.M., Abdullahi, M.S., Ibrahim, Z.Y.Y. et al., 2015b, 'Phytochemical and antimicrobial evaluation of the methanol stem bark extract of Neocarya macrophylla', Journal of Chemical and Pharmaceutical Research 7(1), 477-481. 